\title{
Development and Role of Flux Coupler in a Coupled Atmosphere - Ocean Modeling System
}

\author{
Subbareddy Bonthu \\ Department of Ocean \\ Engineering and Naval \\ Architecture (OE \& NA), \\ Indian Institute of Technology \\ Kharagpur, \\ Kharagpur - 721302 \\ West Bengal, India.
}

\author{
Kaushik Sasmal \\ Department of Ocean \\ Engineering and Naval \\ Architecture (OE \& NA), \\ Indian Institute of Technology \\ Kharagpur, \\ Kharagpur - 721302 \\ West Bengal, India.
}

\author{
Hari V. Warrior \\ Department of Ocean \\ Engineering and Naval \\ Architecture (OE \& NA), \\ Indian Institute of Technology \\ Kharagpur, \\ Kharagpur - 721302 \\ West Bengal, India.
}

\begin{abstract}
The exchange of momentum and radiation fluxes plays a vital role at the interface of atmosphere and ocean. In the present study an attempt has been made to develop a flux coupling algorithm for coupling atmosphere and ocean models as a single model system. The developed coupler has been used for the Kalpakkam region located in the east coast of India as a case study to understand the coastal processes and effect of thermal water pollution on coastal processes due to the establishment of nuclear power plants. The annual and seasonal variation of air temperature, wind speed, sea surface temperature and radiation fluxes; latent and sensible heat fluxes over the Kalpakkam region for a period of five years (2007 - July 2011) has been observed with available OAFlux data. During this period increasing trend of dynamical and thermodynamical variables has been observed. The Weather Research and Forecast (WRF) model has been configured and used to simulate atmospheric parameters over the Kalpakkam region. Thereafter the developed coupler has been used to extract the wind components and radiation parameters from the WRF model output, wherein the wind and radiation stresses were computed using bulk aerodynamic formulations. The heat fluxes show a positive correlation with the temperature gradient and wind speed. The robustness of developed algorithm was assessed through numerical experiments and statistical methods. The model simulated output and coupler estimated variable of wind speed and radiation fluxes have been validated with the available observations. The model results showed the overestimation of radiation fluxes than the observational data. The overestimated fluxes have been added as a correction factor in the coupler to maintain the constant variation in the fluxes. The comparison ascertains the fact that model and coupler performance is satisfactory in comparison with observational data.
\end{abstract}

\section{General Terms}

Flux Coupler, statistical analysis, algorithm, simulations, coupled models.

\section{Keywords}

Radiative fluxes, momentum fluxes, flux coupling algorithm, WRF model, coupled models, modeling system.

\section{INTRODUCTION}

The momentum and heat fluxes are very important in context to the climate system. It depends on balance between the absorption of heat from the Sun and loss of heat in space through the longwave radiation. Therefore the atmosphereocean should be treated as a single coupled system wherein surface fluxes relates to the conservation of mass, heat, energy, momentum etc. Flux products are important to understand the interaction between atmosphere-ocean system thereby assessing the reliability of coupled models. There exists a need for coupled models in an ocean forecasting system to study and understand atmospheric and ocean dynamics in a better perspective. The coupled models have wide practical utility to understand coastal processes, potential fishing zones, marine transportation and marine ecosystem.

The air-sea fluxes knowledge was expanded based on MoninObukhov similarity theory for surface boundary layers and using direct and indirect techniques of measuring the fluxes. The air-sea fluxes are necessary parameters for providing boundary conditions to couple atmospheric and oceanic circulation models, which are used to forecast weather and climate. Flux parameterisation improvement depends upon the wind speed and atmospheric stability and ocean state because the variation of turbulent transfer coefficients is proportional to wind speed, wave steepness, wave age, direction of wave propagation relative to the wind direction, presence of absence of swell, wave breaking and white-capping, wind history, SST, surfactants and rain. The air-sea fluxes products have been measured based on ship's routine weather observations, satellite retrievals, atmospheric and ocean reanalyses, and output of Numerical Weather Prediction (NWP) models. The calibration and validation of air-sea flux products have been carried out based on the high quality observations from the ocean flux reference sites, from selected government and commercial vessels. Fundamentally the air-sea flux exchange means that the loss from the atmosphere must be gained by the ocean, or vice versa.

The air-sea interface depends upon the fastest variations being associated with the diurnal cycle of sunshine and weather conditions. Helen [1] has combined the General Ocean Turbulence Model and the Hadley Centre Ocean Carbon Cycle model to explore the dependencies of air-sea carbon fluxes on physical and marine biological variability. The development of flux coupling algorithm has been initiated to study the role of atmosphere and ocean forcing parameters on the near-shore environmental conditions. The hydrodynamic 
interaction of waves and currents during the Thane cyclone have been explained with dynamical parallel coupling of ADCIRC-SWAN model by exchanging momentum and radiation stress [2]. In the present study, the coupling algorithm acts as an interface between two independent stateof-art models i.e. atmosphere and ocean. It calculates the momentum and heat fluxes from the atmosphere (WRF) model and then transfer to the ocean model (POM). It makes the optimal interpolation of data to provide the specified grid resolution to the ocean model. The atmosphere parameters like wind speed and radiation fluxes (latent heat, sensible heat, longwave radiation and shortwave radiation) and ocean parameter like sea surface temperature are extracted from the WRF and POM models respectively. These parameters are used to study their effect on the coastal processes, coastal activity like thermal water dispersion from outfall location of nuclear plants and circulation features along the Kalpakkam coast. The accuracy of the flux coupling algorithm is tested with available observational data. It has been used as an application for the development of a regional scale coupled modelling system for the Kalpakkam region.

\section{DEVELOPMENT OF FLUX COUPLING TOOL-KIT (FCTK)}

The FCTK has a flux coupling algorithm to combine the atmosphere and ocean models and to supply the data for surface forcing and lateral boundary conditions (Fig. 1). The flux coupling algorithm is used to calculate momentum and heat fluxes by utilizing bulk aerodynamic formulations. The momentum and heat fluxes play a crucial role at the interface to couple the atmosphere and ocean and these two quantities govern the exchange of energy between these two systems. The algorithm of flux coupler has been attached in the appendix. The momentum flux is a major driving force for the ocean basin scale circulation [3] and [4] while the heat flux is important to determine thermal properties of the upper ocean. Both contribute towards turbulence mixing within the oceanic surface mixed layer; therefore both these fluxes are prerequisites for the prediction of SST variability.

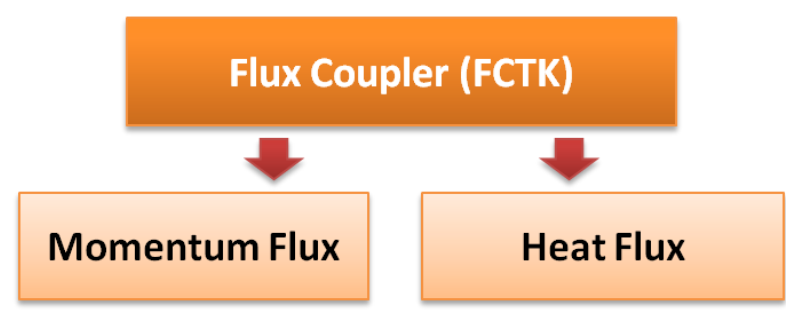

Fig. 1: Flow chart of flux coupler.

The momentum flux is calculated from the zonal and meridional wind components from WRF model output by using the formula:

$$
\begin{aligned}
& \tau=\frac{\rho_{\text {air }}}{\rho_{\text {water }}} C_{D} U^{2} \\
& \frac{\rho_{\text {air }}}{\rho_{\text {water }}}=\frac{1.226}{1.025 \times 10^{3}} \\
& U=\sqrt{u^{2}+v^{2}}
\end{aligned}
$$

where $\tau$ is wind stress, $\rho_{\text {air }}$ and $\rho_{\text {water }}$ are density $\left(\mathrm{kgm}^{-3}\right)$ of air and water, $C_{D}$ is the drag coefficient, $U$ is wind speed, $u$ and $v$ are the zonal and meridional components of wind. The drag coefficient $\left(C_{D}\right)$ depends on the roughness length and wind speed, wave age (ratio of local friction velocity to the phase speed of dominant spectral component), and wave steepness. In the Kalpakkam region the significant wave height is less than $1 \mathrm{~m}$ and moreover the roughness length and wave steepness are insignificant so that under the neutral atmospheric stability, the drag coefficient over the sea surface is linearly dependent on the wind speed [5] and it can be expressed as

$$
C_{D}=\left(0.78+0.475 \times \alpha^{1 / 2} U\right) \times 10^{-3}
$$

where $\alpha$ is the Charnock coefficient Various authors has reported different values of $\alpha$ ranging from 0.012 [6], 0.0144 [7] and 0.0185 [8]. The ocean surface heat fluxes are derived from the WRF model output and are used as forcing components to the ocean model (POM) through the FCTK. The heat flux at the ocean surface $\mathrm{Q}_{\mathrm{NET}}$ is calculated using the following bulk formulation [9]

$$
Q_{\mathrm{NET}}=Q_{\mathrm{SW}}^{\text {net }}-Q_{\mathrm{LN}}^{\text {net }}-Q_{\mathrm{L}}-Q_{\mathrm{S}}
$$

The enthalpy flux formulation is given by

$$
Q_{\mathrm{T}}=Q_{\mathrm{L}}+Q_{\mathrm{S}}
$$

The $Q_{\mathrm{SW}}^{\text {net }}, Q_{\mathrm{LN}}^{\text {net }}$ are the radiative components of shortwave and long-wave radiations Where,

$$
\begin{cases}Q_{\mathrm{NET}}=\text { Net heat flux } & Q_{\mathrm{SW}}^{\text {net }}=\text { Net Shortwave radiation } \\ Q_{\mathrm{S}}=\text { Sensible heat flux } & Q_{\mathrm{L}}=\text { Latent heat flux } \\ Q_{\mathrm{LN}}^{\text {net }}=\text { Net longwave radiation } & \end{cases}
$$

\section{METHODOLOGY}

The atmospheric and oceanic variables are derived from the OAFlux data, which is a blended product of satellite retrievals and Numerical Weather Prediction (NWP) models. Similarly, predicted atmospheric and oceanic variables are derived from the WRF model using coupling algorithm. The seasonal and annual variation of wind speed, air temperature, sea surface temperature, latent heat flux and sensible heat fluxes have been measured over the coastal Kalpakkam during the period of 2007- July 2011. The statistical analysis such as mean, standard deviation, coefficient of variation and correlation factor was carried out using the observational data during that period. The WRF model is then used to simulate high resolution three nested domains having a coarser grid resolution of $1.5 \mathrm{Km}$ for the year of 2009 at coastal Kalpakkam (Fig. 2). The WRF model predicts the atmospheric variables such as wind speed, air temperature, relative humidity, downward shortwave radiation flux, latent heat flux, sensible heat flux, net long wave radiation flux. Statistical methods have been used in this study to find the bias, root mean square (RMS) difference, scattering index (SI) and correlation coefficient $(\mathrm{R})$ which have been defined by following relations.

$$
\begin{aligned}
& \text { Bias }=\frac{1}{N} \sum_{j=1}^{N}\left(X_{j}-Y_{j}\right) \\
& R M S=\sqrt{\frac{1}{N} \sum_{j=1}^{N}\left(X_{j}-Y_{j}\right)^{2}}
\end{aligned}
$$




$$
\begin{gathered}
S I=\frac{\sqrt{\frac{1}{N} \sum_{j=1}^{N}\left[\left(X_{j}-\bar{X}\right)-\left(Y_{j}-\bar{Y}\right)\right]^{2}}}{\bar{Y}} \\
R=\frac{\sum_{j=1}^{N}\left(X_{j}-\bar{X}\right)-\left(Y_{j}-\bar{Y}\right)}{\sqrt{\sum_{j=1}^{N}\left(X_{j}-\bar{X}\right)^{2}\left(Y_{j}-\bar{Y}\right)^{2}}}
\end{gathered}
$$

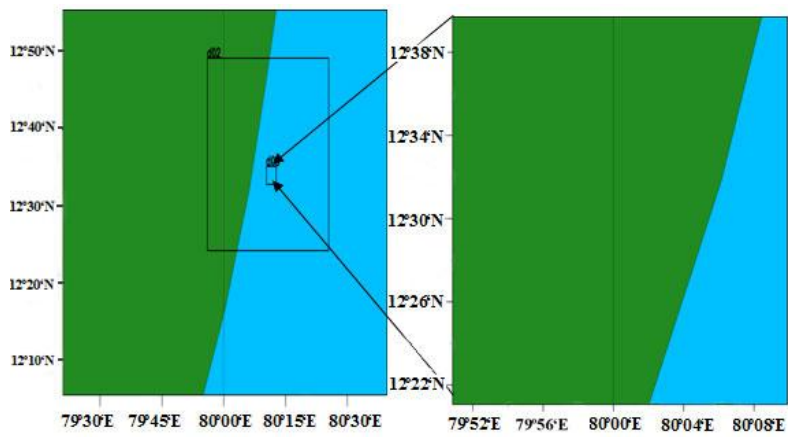

Fig. 2: Nested WRF model domain over the Kalpakkam Region.

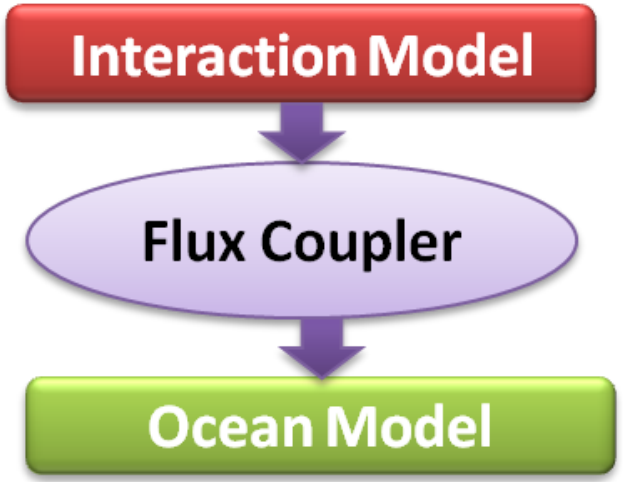

Fig. 3: Interaction of 'Flux Coupler' between two inter dependent atmosphere and ocean models.

The interaction between two models has been achieved using the flux coupler is shown in Fig. 3. It consists of momentum and heat fluxes modules to calculate momentum and heat fluxes using bulk aerodynamic formulations. The flux calculation subroutine involves flux coupling mechanism using momentum and heat flux subroutines called as a Flux Coupling Tool-Kit (FCTK).

The FCTK has the flexibility to provide either momentum flux or heat flux or a combination of both into the ocean model. Thus the information of fluxes is passed to ocean model as surface boundary conditions in a regular interval of time using FCTK. It also takes care of data exchange for surface and lateral boundary conditions in the sequential mode without any time lag (Fig. 4).

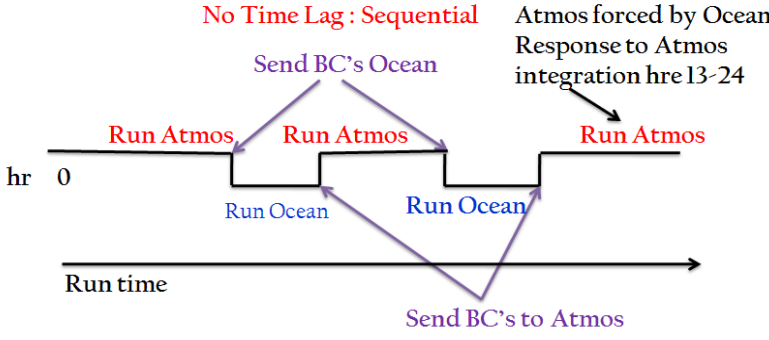

Fig. 4: Sequential simulation flow chart of coupled atmosphere-ocean modelling system.

\section{RESULTS AND DISCUSSIONS}

4.1 Variation of Atmosphere and Ocean Parameters over the Kalpakkam Region for the period of 2007 - 2011

The atmosphere and ocean parameters like wind speed, air temperature, sea surface temperature, latent and sensible heat flux are analyzed for five years (2007-2011) over the Kalpakkam region. The data clearly exhibits the Objectively Analyzed air-sea heat fluxes (OAFlux). It is a blended product of satellite and NWP models and available with $0.25^{\circ} \times 0.25^{\circ}$ resolution. The variation of wind speed, Air temperature and Sea Surface Temperature observed for five years period (2007-2011) as shown in Figure 5. The wind speed clearly exhibits the seasonal and annual variation along the coastal Kalpakkam, Bay of Bengal. It varies between 6$11.8 \mathrm{~ms}^{-1}$ during the southwest monsoon season and between 2-6 $\mathrm{ms}^{-1}$ during pre- and post-monsoon period for the five year (2007-2011) period (Fig. 5c). The variation of air temperature and sea surface temperature also shows the same annual and seasonal trend. The mean values of air temperature and SST are shown in Table 1 for the period of $2007-2011$. The variation of sensible and latent heat fluxes are shown in the Fig. 6 a, b, depict seasonal and annual variation for the period of five (2007-2011) years. The sensible heat flux varies from -5 to $34 \mathrm{Wm}^{-2}$. The variation of sensible heat flux indicates that the release of sensible heat flux is more during the southwest monsoon season than the northeast monsoon season. In case of latent heat flux, similar seasonal and annual trend has been observed, and quantitatively more latent heat flux is observed during the southwest monsoon season that varies from 130 to $230 \mathrm{Wm}^{-2}$. During the northeast monsoon season, it varied from 70 to $170 \mathrm{Wm}^{-2}$. For the five years period, latent heat flux is higher during southwest than the northeast monsoon season. The atmosphere and oceanic parameters influence one another through the variation of their magnitude in the weather system.

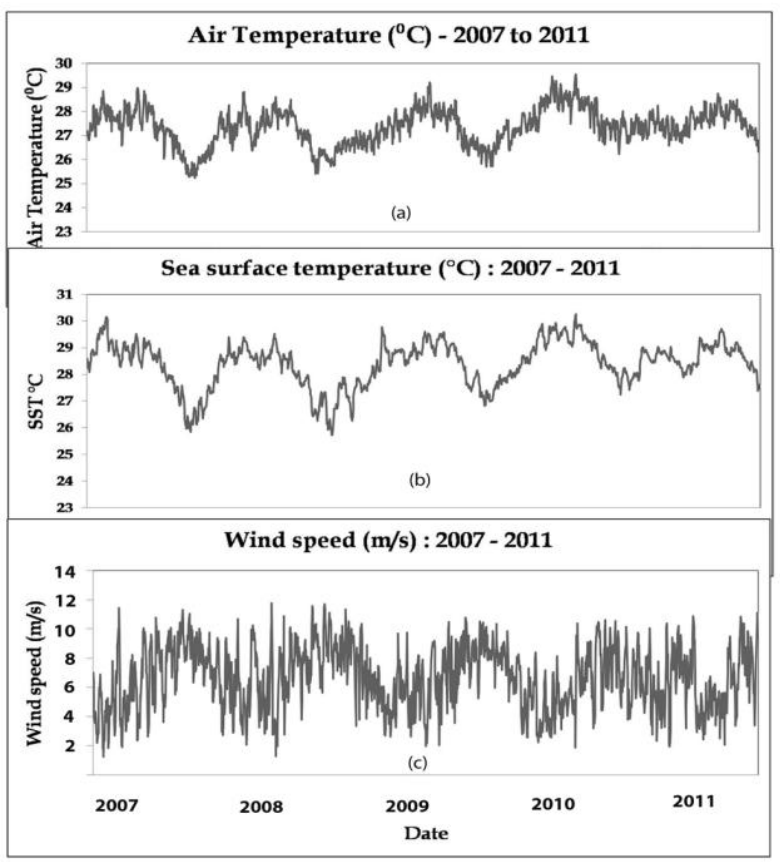

Fig. 5: Monthly variation of (a) Air temperature $\left({ }^{\circ} \mathrm{C}\right)(\mathrm{b})$ SST $\left({ }^{\circ} \mathrm{C}\right)$, and $(\mathrm{c})$ wind speed $(\mathrm{m} / \mathrm{sec})$ for the period of 2007- July 2011. 


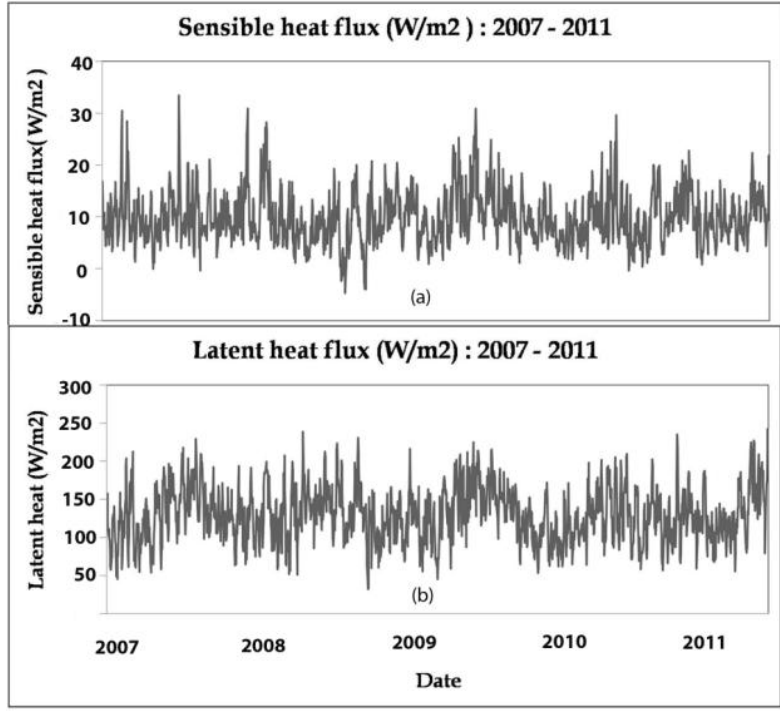

Fig. 6: Monthly variation of (a) Sensible heat flux $\left(\mathrm{W} / \mathrm{m}^{2}\right)$ (b) Latent heat flux $\left(\mathrm{W} / \mathrm{m}^{2}\right)$ for the period of 2007 - July 2011.

The relation between these two different parameters is obtained by the correlation coefficient which gives the dependence between them. The relation between the temperature gradient (temperature difference between air temperature and sea surface temperature) and sensible heat flux (Fig.7a) was estimated and showed a positive correlation with the $\mathrm{R}^{2}$ value of 0.54 . Similarly, the wind speed and the latent heat flux (Fig.7a) showed a positive correlation with the $\mathrm{R}^{2}$ value of 0.63 for the period of five years (2007-2011). The statistical analysis of heat fluxes with the variation of temperature gradient and wind speed shows significant changes along the coast of Kalpakkam region. The statistical analysis such as mean, standard deviation and coefficient of variance were also estimated for the wind speed, air temperature, sea surface temperature, sensible and latent heat flux along the coastal Kalpakkam during the period of 2007July 2011 (Table 1). The mean of wind speed is $6.65 \mathrm{~ms}^{-1}$ and its standard deviation and coefficient of variance are 2.15 and 0.32 respectively for the five years. The heat fluxes such as latent and sensible heat fluxes exhibit high standard deviation compare to the other parameters. The coefficient of variance of sea surface temperature is less compared to the other atmosphere and oceanic parameters. Hence the statistical analysis of atmosphere and oceanic parameters clearly revealed that the momentum and heat fluxes are highly variable due to the large variation as observed from the mean values for the period of 2007- July 2011.

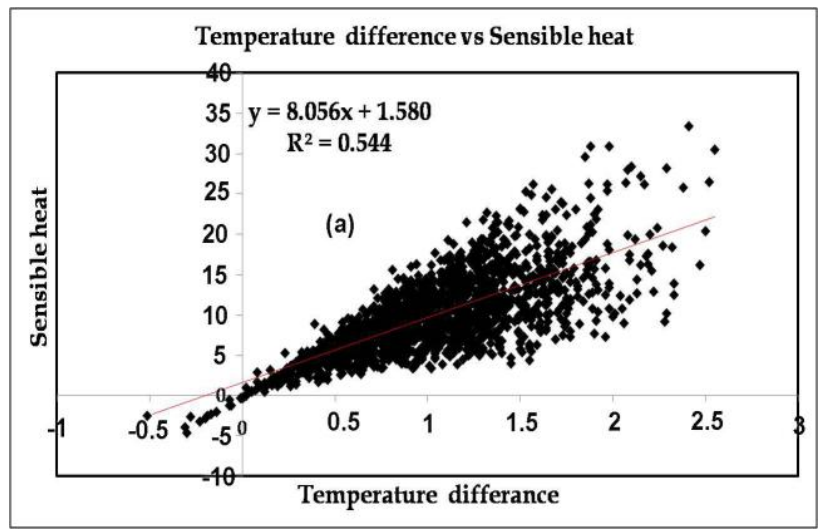

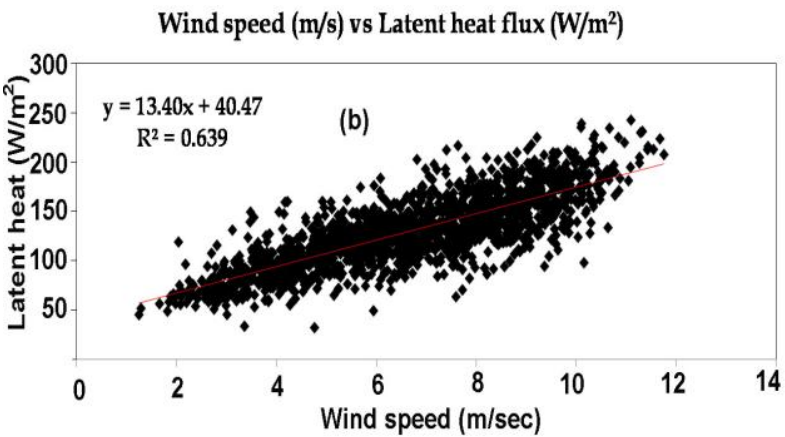

Fig. 7: Estimation of correlation factor between (a) temperature gradient and sensible heat flux (b) wind speed and latent heat flux for the period of 2007 - July 2011.

Table 1. Statistical analysis of atmosphere and oceanic parameters along the coastal Kalpakkam.

\begin{tabular}{|c|c|c|c|}
\hline Parameters & mean & $\begin{array}{c}\text { Standard } \\
\text { deviation }\end{array}$ & $\begin{array}{c}\text { Co-efficient } \\
\text { of Variance }\end{array}$ \\
\hline Wind Speed $\left(\mathbf{m s}^{-1}\right)$ & 6.65 & 2.15 & 0.32 \\
\hline $\begin{array}{c}\text { Air temperature } \\
\left({ }^{\circ} \mathbf{C}\right)\end{array}$ & 27.37 & 0.77 & 0.33 \\
\hline $\begin{array}{c}\text { Sea Surface } \\
\text { temperature }\left({ }^{\circ} \mathbf{C}\right)\end{array}$ & 28.4 & 0.85 & 0.03 \\
\hline $\begin{array}{c}\text { Sensible heat flux } \\
\left(\mathbf{W m}^{-2}\right)\end{array}$ & 9.87 & 5.02 & 0.51 \\
\hline $\begin{array}{c}\text { Latent Heat flux } \\
\left(\mathbf{W m}^{-2}\right)\end{array}$ & 129.6 & 36.06 & 0.28 \\
\hline
\end{tabular}

\subsection{Atmospheric Parameters from Flux} Coupling Tool-Kit over the Coastal Kalpakkam

Atmosphere plays an important role in the diurnal variability and weather change over the Kalpakkam region. There is a need for high-resolution atmospheric forecast over Kalpakkam region due to the establishment of nuclear power plants. Atmospheric parameters play a key role in deciding the fate of thermal plume dispersion in the near vicinity of Kalpakkam coast.

Several authors have explained the variability of atmosphere dynamics and thermodynamics over the Kalpakkm region in the hypothetical accidental scenario of nuclear power plants. The variation of atmospheric dynamics and thermodynamic variables has been simulated using high resolution WRF model over the Kalpakkam region [10]. The wind distribution off Kalpakkam is shown in Figure 8 for the pre- and postmonsoon seasons commonly called the transition periods for the summer and winter monsoons. For the period of March to May, the magnitude of wind varies from 3.26 to $5.91 \mathrm{~ms}^{-1}$. During March and April, easterly wind prevails and during May it gradually becomes Southerly. During October to December, the magnitude of wind varies from 1.53 to $6.8 \mathrm{~ms}^{-}$ 1 . In October, the magnitude of wind is very small i.e. less than $3 \mathrm{~ms}^{-1}$ in southerly direction. The direction of wind is from east to west and east to south west in remaining months. This wind pattern clearly exhibits reversal wind system during the southwest and northeast monsoons and additionally the weak wind magnitude clearly represents the transition period in between the monsoons. 
Sensible heat flux (SHF) transfer is a function of the vertical temperature gradient and degree of turbulence or eddy conductivity above the sea surface. Due to the lack of information on eddy conductivity (diffusivity), it is a general practice to relate sensible heat transfer to temperature difference between atmosphere and ocean. The variation of sensible heat flux is very small over the ocean. In a climatological perspective variation of sensible heat flux gradually decreases from March to May and slowly increases from October to December over the Kalpakkam region. On the other hand, estimation of Latent Heat Flux (LHF) (Fig. 9) is obtained by relating evaporation to vapor pressure difference and wind speed. The energy loss caused by evaporation is a function of sea surface temperature. In the month of April, the LHF varies in the range between 129.4 $130 \mathrm{Wm}^{-2}$. During March to May it remains almost same and varies in the range between $142.4-148.8 \mathrm{Wm}^{-2}$. However, from October to December, the LHF gradually increases and varies in the range $159.3-269.4 \mathrm{Wm}^{-2}$, the highest value has been observed in December $\left(269.4 \mathrm{Wm}^{-2}\right)$.

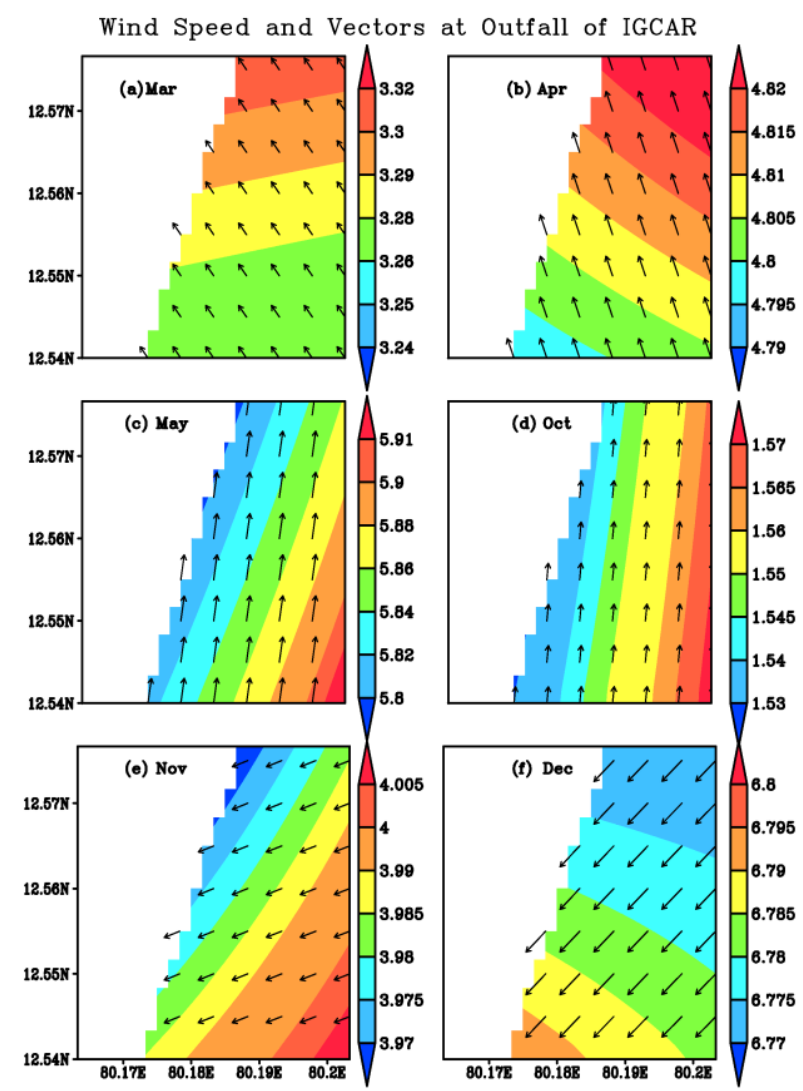

Fig. 8: (a, b, c , d, e, and f) are showing the monthly averaged wind speed $\left(\mathrm{ms}^{-1}\right)$ and wind vectors over the outfall region of Kalpakkam in pre- and post-monsoon seasons.
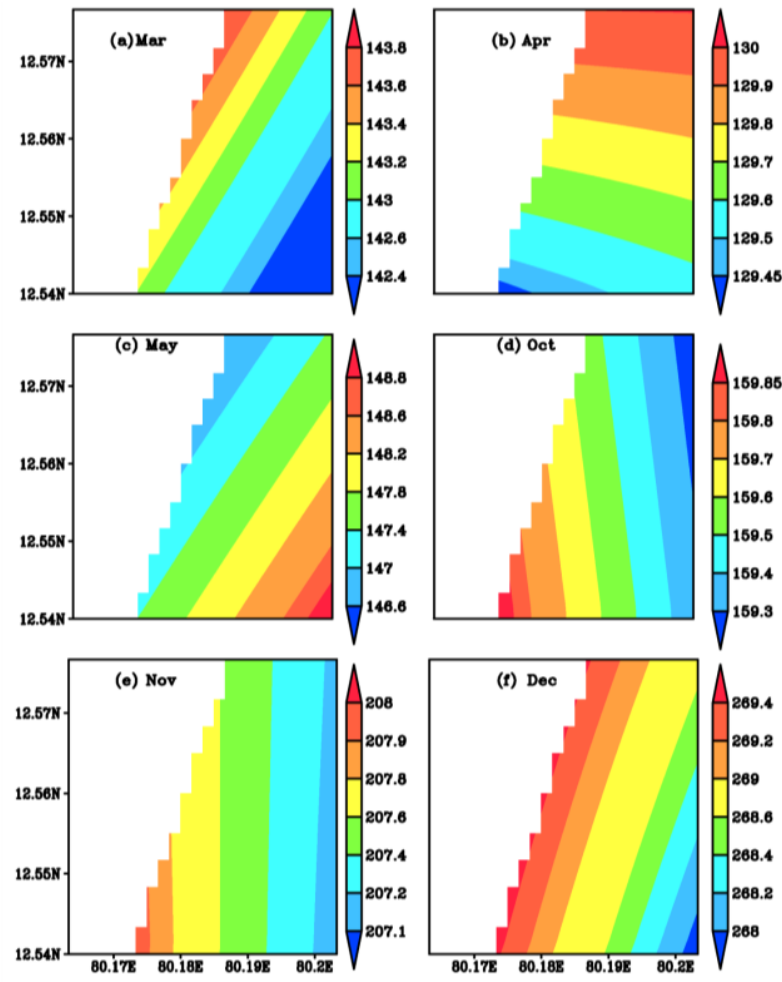

Fig. 9: Panels (a), (b) and (c) show the variation of monthly averaged latent heat flux $\left(\mathrm{Wm}^{-2}\right)$ during pre-

monsoon season; (d), (e) and (f) show the monthly variation of latent heat flux during post-monsoon season in the outfall region of Kalpakkam.
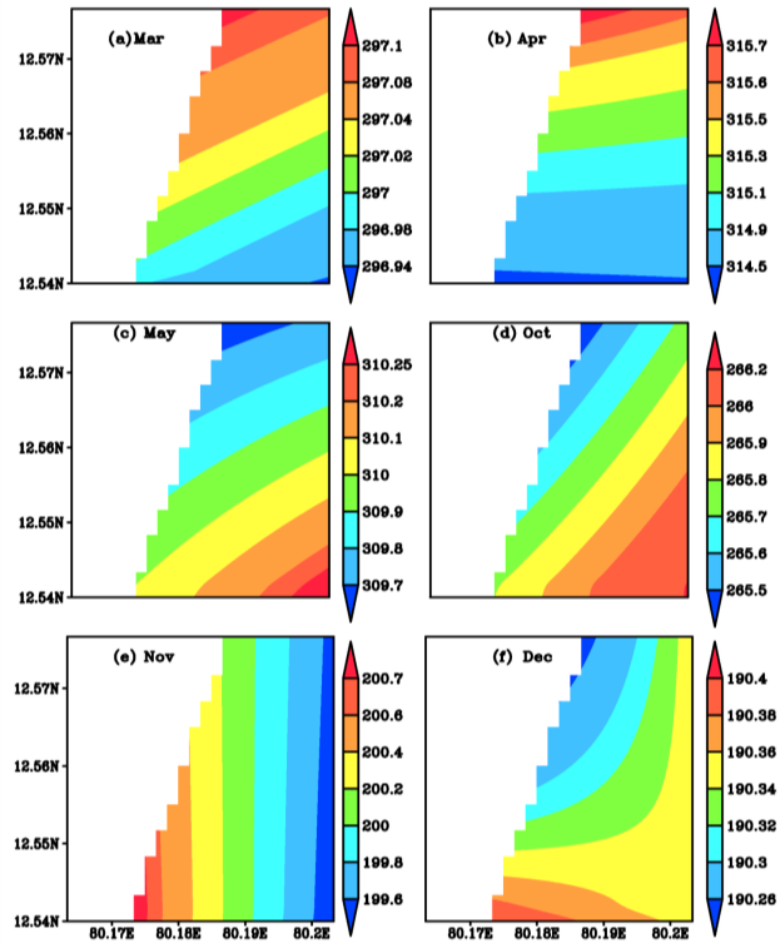

Fig. 10: Panels (a), (b), and (c) show the variation of monthly averaged shortwave radiation during the premonsoon season; (d), (e), and (f) show the monthly variation of shortwave radiation during post-monsoon season in the outfall region of Kalpakkam. 
Shortwave radiation (SWR) (as in Fig. 10) is a function of the sun's altitude and cloud cover. In the pre-monsoon season the short wave radiation shows higher values and it varied in the range between $296.94-315.7 \mathrm{Wm}^{-2}$. During the postmonsoon season it varies in the range between 190.26-266.2 $\mathrm{Wm}^{-2}$ and which was less than the pre-monsoon season. The minimum and maximum values are observed in the month of December (190.26 $\left.\mathrm{Wm}^{-2}\right)$ and April (315.7 $\left.\mathrm{Wm}^{-2}\right)$ respectively. It is observed that all these fluxes have their effect on thermal plume dispersion, recirculation of thermal plume and sea surface circulation.

\section{VALIDATION OF FLUX COUPLING ALGORITHM AND THE PERFORMANCE OF WRF MODEL}

Modelling and statistical analysis of atmospheric parameters can help to know the model performance and relation between predicted and observational data. The modeled wind data over the Kalpakkam region is compared with the OAFlux observational data. The WRF model predicted wind data exhibits the same trend as the OAFlux data (shown in Fig. 11). The predicted wind speed and observational data shows positive correlation with $\mathrm{R}^{2}$ value of 0.74 .

The wind speed obtained from the Flux coupled algorithm based on WRF model and OAFlux data are shown in Fig. 11 and 12. The statistics used are bias, root-mean square (RMS) difference, Scatters Index (SI), and correlation coefficient (R) which are estimated and tabulated in the Table 2. Modeling of the atmospheric parameters matches well with the blended data of satellite and Flux coupler extracted data. The modeled latent and sensible heat fluxes are compared to the blended satellite and NWP models observations with an error factor + $60 \mathrm{Wm}^{-2}$

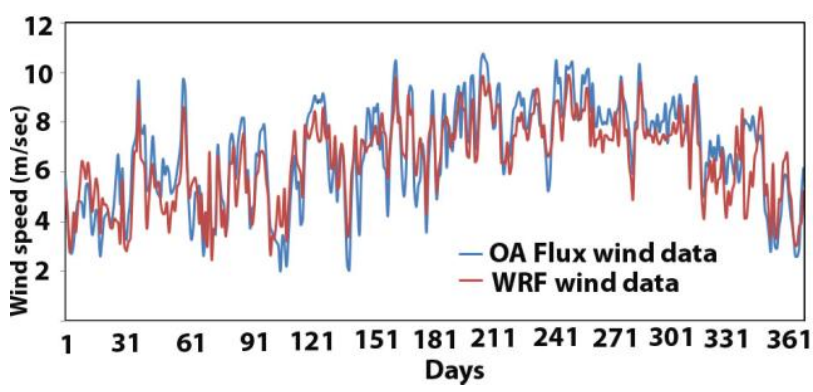

Fig. 11: Comparison of WRF model predicted wind data and OAFlux observational data for the year of 2009 over

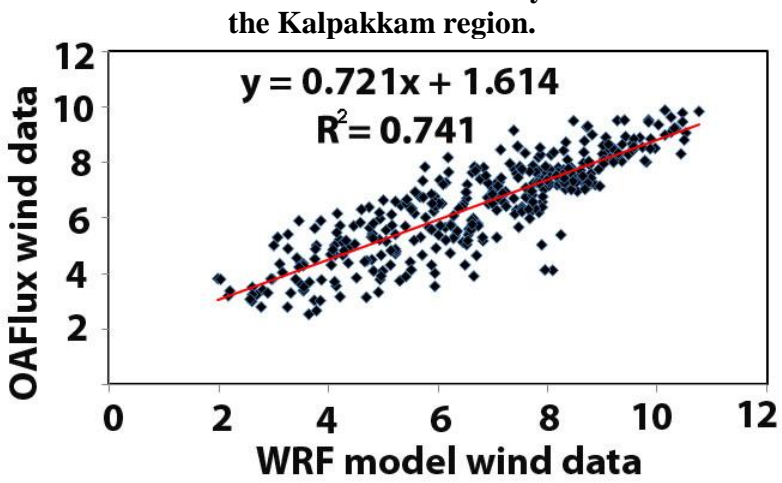

Fig. 12: Correlation of WRF model predicted wind data and OAFlux observational data for the year of 2009 over the Kalpakkam region.
Table 2. Statistical analysis of wind speed significance between WRF model and OA Flux data along the coastal Kalpakkam

\begin{tabular}{|l|l|}
\hline Total number of sample (Days) $\mathrm{n}$ & 365 \\
\hline Observed mean & 6.72 \\
\hline Model mean & 6.46 \\
\hline Bias & 0.26 \\
\hline Root Mean Square (RMS) difference & 1.065 \\
\hline Scatter index (SI) & 0.175 \\
\hline Correlation coefficient (R) & 0.83 \\
\hline
\end{tabular}

\section{CONCLUSIONS}

The flux coupling algorithm is used as an interface between atmosphere and ocean model. It is used to extract the wind components and radiation parameters from the WRF model output, wherein the wind and radiation stresses was computed using bulk aerodynamic formulations. OAFlux data was used to observe the seasonal and annual variation of air temperature, wind speed, sea surface temperature and radiation fluxes; latent and sensible heat fluxes over the Kalpakkam region for a period of five years (2007-July 2011). The heat fluxes show a positive correlation with the temperature gradient and wind speed. The estimated correlation factor of radiation fluxes are 0.54 and 0.63 respectively. The WRF model was used to simulate atmospheric parameters over the Kalpakkam region and validate the variation of wind speed and radiation fluxes with the available observations. The correlation coefficient between the model predicted wind speed and observational data was 0.83 . The comparison ascertains the fact that model performance is satisfactory in comparison with observational data. In case of radiation fluxes, the model overestimates the predicted value of fluxes by a factor of $+60 \mathrm{Wm}^{-2}$. In the present study, variable wind speed, short wave radiation and latent heat flux were used for thermal plume dispersion as a case study for Kalpakkam coast during pre- and post-monsoon seasons. The robustness of developed algorithm was assessed through numerical experiments and statistical analysis

\section{ACKNOWLEDGMENTS}

We greatly acknowledge the Indira Gandhi Centre for Atomic Research, Kalpakkm for providing fund for the project on 'Development of Real-time Environmental Modelling system for Kalpakkam'. We express our deep gratitude to Dr. Venkatesan for his unending support to carry out this work. We thank to Dr. Prasad Kumar Bhaskaran for giving his suggestions and sharing information to improve this research work.

\section{REFERENCES}

[1] Helen, K., Merchant, C. J., Filipiak, M. J., Jeffery, C. D., and Gentemann. C. L. 2009. The Impact of Diurnal Variability in Sea Surface Temperature on the Atlantic Sea-Air CO2 flux. Atmospheric Chemistry and Physics. $9,529-541$.

[2] Bhaskaran, P. K., Nayak, S., Bonthu, S. R., Murthy, P. L. N., and Sen, D. 2013. Performance and validation of Coupled Parallel ADCIRC-SWAN for Thane cyclone in the Bay of Bengal. Environmental Fluid Mechanics, DOI $10.1007 / \mathrm{s}$ 10625-013-9284-5. 
[3] Chen, D., Busalacchi, A. J., and Rothstein, L. M. 1994. The roles of vertical mixing, solar radiation, and wind stress in a model simulation of the sea surface temperature seasonal cycle in the tropical Pacific Ocean. Journal of Geophysical Research. 99(20), 345-20 359.

[4] Shriver, J. F., Hurlburt, H. E., 1997. The contribution of the global thermohaline circulation to the Pacific to Indian Ocean through flow via Indonesia. Journal of Geophysical Research. 102, 5491-5511.

[5] Guan, C. and Xie, L. 2004. On the Linear Parameterization of Drag Coefficient over Sea Surface. Journal of Physical Oceanography. 34, 2847-2851.

[6] Charnock, H. 1955. Wind stress on a water surface. Quarterly Journal of the Royal Meteorological Society. 81, 639-640.

[7] Garratt, J. R. D., 1977. Review of drag coefficients over oceans and continents. Monthly Weather Review. 105, 915-929.

[8] Wu, J., 1980. Wind-stress coefficients over sea surface near neutral conditions-A revisit. Journal of Physical Oceanography $10,727-740$.

[9] Louis, J., Tiedtke, M., and Geleyn, J. F., 1982. A short history of PBL parameterization at ECMWF. Workshop on Planetary Boundary Layer Parameterization. ECMWF, 59-80.

[10] Bonthu, S. R., Sasmal, K., Warrior, H., and Maity, S. 2013. Development of an automated Regional Coupled Atmosphere-Ocean modeling System for coastal Kalpakkam. International Journal of Ocean and Climate systems (IJOCS). 4(2), 87-116.

\section{APPENDIX}

The flux coupling algorithm has been developed using FORTRAN code with NetCDF support. It extracts the atmospheric variables from the WRF model and then calculates the momentum and radiation stresses from the bulk aerodynamic formulations. The algorithm of flux coupler has been attached below.

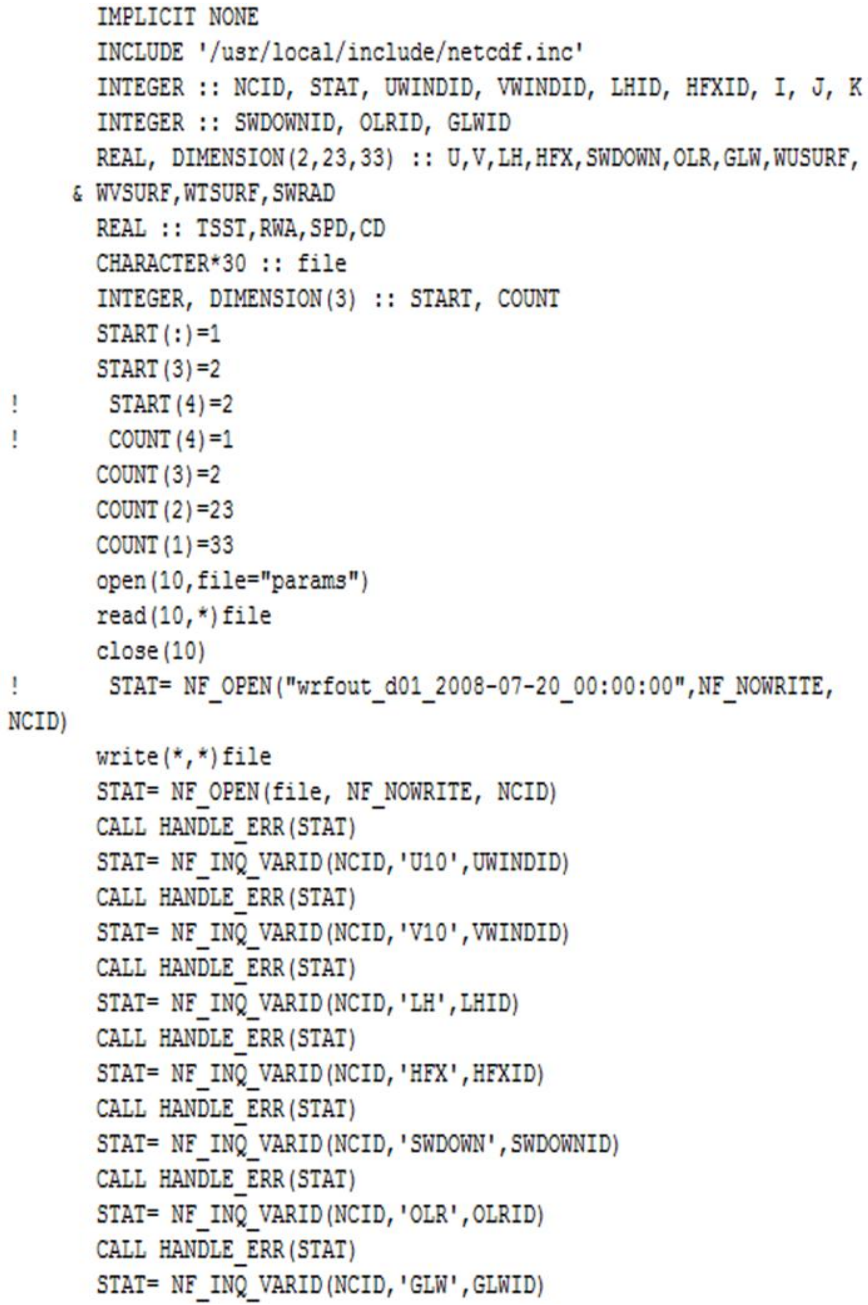


STAT = NF GET VARA REAL (NCID, UWINDID, START, COUNT, U) CALL HANDLE_ERR (STAT)

STAT $=$ NE_GET_VARA_REAL (NCID, VWINDID, START, COUNT, V)

CALL HANDLE $\bar{E} R R$ (STTAT)

STAT = NF_GET VVARA_REAL (NCID, LHID, START, COUNT, LH)

CALL HANDLE_ERR (STAT)

STAT = NF GET VARA REAL (NCID, HFXID, START, COUNT, HFX)

CALL HANDLE_ERR (STAT)

STAT $=$ NF_GET_VARA_REAL (NCID, SWDOWNID, START, COUNT, SWDOWN)

CALL HANDLE ERR (STAT)

STAT $=$ NF_GET_VARA_REAL (NCID, OLRID, START, COUNT, OLR)

CALL HANDLE ERR (STAT)

STAT $=$ NF_GET_VARA_REAL (NCID, GLWID, START, COUNT, GLW)

CALL HANDLE $\bar{E}$ RR (STAT)

FORALL $(I=1: 288, J=1: 189)$ SST $(I, J)=S S T(I, J)+273.12$

DO $\mathrm{K}=1,8$

DO $\mathrm{J}=1,23$

DO $I=1,33$

$\mathrm{SPD}=\mathrm{S} Q \mathrm{RT}(\mathrm{U}(\mathrm{I}, \mathrm{J}, \mathrm{K}) * \star 2+\mathrm{V}(\mathrm{I}, \mathrm{J}, \mathrm{K}) * \star 2)$

$\mathrm{CD}=(7.5 \mathrm{E}-4+6.7 \mathrm{E}-5 * \mathrm{SPD})$

$\mathrm{RWA}=1.226 \mathrm{e}-3 / 1.025$

$\operatorname{WRITE}(*, *)$ SPD, CD, RWA

WUSURF $(I, J, K)=-1 * R W A * C D * S P D * U(I, J, K)$

WVSURF $(I, J, K)=-1 * R W A * C D * S P D * V(I, J, K)$

WRITE $(*, *) \operatorname{WUSURF}(I, J), \operatorname{WVSURF}(I, J)$

WTSURF $(I, J, K)=(L H(I, J, K)+H F X(I, J, K)+$

\& $(\operatorname{GLW}(I, J, K)-O L R(I, J, k))) /(1025 * 3986)$

$\operatorname{SWRAD}(I, J, K)=\operatorname{SWDOWN}(I, J, K) /(1025 * 3986)$

ENDDO

ENDDO

ENDDO

$\mathrm{DO} \mathrm{K}=1,8$

DO $\mathrm{J}=1,23$

WRITE $\left(21,{ }^{\prime}(1000\right.$ (F12.8, 2X)) ') (WUSURF (I, J, K), I=1,33)

WRITE $\left(22,{ }^{\prime}(1000(F 12.8,2 X)) '\right)$ ) (WVSURF $(I, J, K), I=1,33$ )

WRITE $\left(23\right.$, ' $^{\prime}(1000(\mathrm{~F} 12.8,2 \mathrm{X}))$ ') (WTSURF $\left.(I, J, K), \quad I=1,33\right)$

$\operatorname{WRITE}\left(24,{ }^{\prime}(1000(\mathrm{~F} 12.8,2 \mathrm{X}))\right.$ ') (SWRAD $\left.(I, J, K), \quad I=1,33\right)$

ENDDO

ENDDO

STAT $=$ NF_CLOSE (NCID)

STOP

END

-- !

SUBROUTINE HANDLE_ERR (STAT)

INCLUDE '/usr/local/include/netcdf.inc'

INTEGER, INTENT ( IN) : : STAT

IF ( STAT /= NF_NOERR ) THEN

PRINT *, TRIM $(\overline{\mathrm{N}}$ __STRERROR (STAT) )

STOP

END IF

END SUBROUTINE HANDLE_ERR 